\title{
A educação do garoto selvagem de Aveyron e a proposta contemporânea de escolarização de alunos com transtorno do espectro autista: possibilidades de leitura
}

\author{
Tais Guareschi* \\ Maria Inês Naujorks**
}

\section{Resumo}

Neste artigo, temos como objetivo analisar a experiência pedagógica de Jean Itard com o menino selvagem, refletindo sobre a presença do ideário desse médico-pedagogo na proposta contemporânea de escolarização de alunos com transtorno do espectro autista. Itard, ao contrário de outros médicos, apostou na educabilidade de Victor, supondo que suas dificuldades eram decorrentes do longo abandono vivenciado. A proposta de Itard era de caráter eminentemente educativo, tendo como premissas orientadoras que o conhecimento e as ideias advêm das sensaçóes e que cada sentido deveria ser estimulado isoladamente. Com base na análise empreendida sobre essa experiência pedagógica, refletimos sobre a presença desse ideário na educação de alunos com autismo. Para tanto, propomos a discussão a partir de um ponto central: a primazia do método de ensino na proposta pedagógica de Itard. $\mathrm{Na}$ contemporaneidade, a inclusão escolar de alunos com transtorno do espectro autista impele os professores a demandar um método de ensino, que garanta como resultado a aprendizagem dos conhecimentos escolares. Atentamos para a possibilidade dessa demanda repetir o cerne da proposta de Itard, que era o método. Tendo este como foco central, as manifestaçóes singulares poderão ser apagadas ou tomadas como um entrave a ser superado na educação desses sujeitos.

Palavras-chave: Garoto selvagem de Aveyron; Transtorno do espectro autista; Educação inclusiva.

\footnotetext{
* Doutoranda em Educaçáo pela Universidade Federal de Santa Maria, Santa Maria, Rio Grande do Sul, Brasil.

** Professora doutora da Universidade Federal de Santa Maria, Santa Maria, Rio Grande do Sul, Brasil.
} 


\title{
The education of the wild boy of Aveyron and contemporary proposal for school students with autism spectrum disorder: reading possibilities
}

\begin{abstract}
In this article, we have to analyze the educational experience of Jean Itard with the wild boy, reflecting on the presence of the ideas of this medical pedagogue in contemporary proposal for school students with autism spectrum disorder. Itard, unlike other physicians, bet on Victor educability, assuming that their difficulties were arising from long experienced abandonment. The proposed Itard was eminently educational nature, with the guiding assumptions that knowledge and ideas stem from feelings and that each sense should be encouraged in isolation. Based on the analysis undertaken on this learning experience, we reflect on the presence of this ideology in students with autism education. Therefore, we propose the discussion from a central point: the primacy of teaching method in the pedagogical proposal of Itard. In contemporary times, the school inclusion of students with autism spectrum disorder compels teachers to demand a teaching method that guarantees results in the learning of school knowledge. We alert to the possibility that demand repeat the core of the proposed Itard, who was the method. Taking this as a central focus, natural events can be deleted or taken as an obstacle to be overcome in the education of these subjects.
\end{abstract}

Keywords: Boy wild Aveyron; Disorder autism spectrum; Inclusive education.

\section{Apresentação}

Os relatórios escritos por Jean Itard, em 1801 e 1806, sobre sua experiência pedagógica com o garoto selvagem de Aveyron são potentes para incitar discussóes sobre a educação na contemporaneidade. É pertinente, em meio às querelas da educação inclusiva, olhar para os relatos de Itard e perguntar o que ainda poderá ser dito sobre a primeira tentativa retratada de ensino no campo da Educação Especial. As atuais políticas públicas de inclusão no Brasil sinalizam para a inserção de todos os alunos no ensino regular, nas classes comuns. A oferta de um ensino para todos tem se constituído um desafio; algo que precisa ser acompanhado e debatido para que as possibilidades de escolarização possam ser inventadas no caso a caso, nas experiências particulares de cada escola.

Diante desse contexto, recorrer à experiência considerada inaugural da Educação Especial poderá propiciar uma reflexão sobre a escolarização de alunos que apresentam particularidades em seu percurso escolar. Neste artigo, nosso olhar se voltará especificamente para a educação de alunos designados, nos campos da psiquiatria e das políticas educacionais, como aqueles com transtorno do espectro autista. Nesse sentido, pretendemos analisar a experiência pedagógica com o menino selvagem, refletindo sobre a presença do ideário de Jean Itard na proposta contemporânea de escolarização de alunos com transtorno do espectro autista. 
A tentativa de civilização do garoto tem início quando, em uma floresta na região de Aveyron, na França, três caçadores o capturaram totalmente nu e com hábitos selvagens com 11 ou 12 anos de idade. O menino já havia sido avistado anteriormente, nessa mesma regiáo, buscando raízes e nozes para se alimentar, no entanto, sempre evitava qualquer tentativa de aproximaçáo das pessoas. No momento em que o capturaram os homens o levaram a um povoado, onde ficou sob a guarda de uma viúva por uma semana, ao final da qual fugiu. Em janeiro de 1800, foi encontrado novamente, ao entrar em uma casa em Saint-Sernin para se aquecer. Nessa residência, permaneceu vigiado por dois ou três dias quando foi transferido para o asilo Saint-Afrique. Após um mês foi encaminhado para a Escola Central de Rodez, instituição em que foi examinado por um professor de história natural, denominado Pierre Bonnaterre.

Em agosto de 1800, o menino é levado por Bonnaterre, a pedido do Ministro do Interior, ao Instituto Nacional de Surdos-Mudos, em Paris. Segundo Itard (2000a, p. 130), o ministro "[...] julgou que a ciência do homem moral poderia tirar algumas luzes desse acontecimento". A chegada do selvagem despertou a curiosidade da sociedade parisiense, a qual se deparou com um menino sujo que apresentava balanceio de corpo, mordia ou arranhava quem se aproximasse, sendo "[...] indiferente a tudo e não dando atenção a nada" (ITARD, 2000a, p. 130).

No instituto, foi observado e avaliado pelo médico Philippe Pinel. Após essa avaliação, Pinel estabeleceu que o menino era idiota, nomeaçáo da deficiência intelectual na época, comparando-o aos pacientes com idiotia de Bicêtre, hospital psiquiátrico em que era médico chefe. Por sua vez, Itard apostou na educabilidade do garoto selvagem, supondo que suas dificuldades eram decorrentes "do longo e total abandono" vivenciado (ITARD, 2000a, p. 134). Para esse médico, o menino havia sido abandonado por volta dos 4 ou 5 anos de idade, e o isolamento do convívio social era a causa do idiotismo aparente, como denominou. Itard o compara a um bebê de dez ou doze meses, que tem "[...] contra si hábitos antissociais, uma renitente desatenção, órgãos pouco flexíveis e uma sensibilidade acidentalmente embotada" (ITARD, 2000a, p. 135).

Em virtude desses pressupostos, Itard afirma que esse era um caso médico e deveria, portanto, receber tratamento da medicina moral. Isto posto, o médico iniciou o tratamento/educação do garoto selvagem a quem chamou de Victor, nome escolhido devido à estima que o menino demonstrava pela exclamação ob!. Assim, a predileção por esse som levou à opção de um nome que terminasse com $o$. O tratamento médico moral proposto ao menino selvagem foi inspirado nos pressupostos filosóficos de Locke e, de forma determinante, nas ideias de cunho empírico-sensualistas de Condillac. O médico declara que, com base nessas concepçôes, estimulou cada órgão do sentido de forma separada, para atingir as metas estabelecidas.

O filósofo Condillac, que influenciou de maneira contundente a proposta de educação de Itard, foi seguidor da doutrina filosófica de Locke, o empirismo, e considerava que as ideias e o conhecimento derivavam das sensaçóes. Em suas formulaçôes, utiliza a metáfora da estátua, em que esta possui a organização interior do ser humano e um espírito desprovido de ideias, já seu exterior é de mármore, o que 
não lhe possibilita utilizar os seus sentidos. Esses sentidos são, então, despertados separadamente, iniciando pelo olfato. Por meio dessa metáfora, o filósofo pretende demonstrar a maneira como surgem as ideias e o conhecimento a partir da ativaçáo de cada sentido (CONDILLAC, 1993).

Mediante a disposição de Itard em empreender o exercício da medicina moral, apostando na educabilidade do garoto, o governo francês o autoriza a realizar esse tratamento no próprio Instituto de Surdos-Mudos, em uma ala separada dos internos surdos, arcando com os custos anualmente. Uma governanta, Madame Guérin, é contratada para auxiliar o médico em seu trabalho. Após dez anos de permanência no instituto, em consequência da estagnação observada em seu desenvolvimento e da perda de interesse do médico-pedagogo, Victor passa a morar em uma casa nas redondezas com sua governanta, tendo suas despesas mantidas pelo governo. Victor faleceu no ano de 1828, quando tinha por volta de 40 anos de idade (BANKS-LEITE; GALVÃO, 2000).

Diante dessa breve descrição sobre a trama da experiência pedagógica de Jean Itard, é possível, neste momento, avançarmos em direção ao objetivo desta escrita. Ao desentrelaçarmos os fios dessa história, procuramos "a persistência silenciosa desse ideário entre nós”, como refere Lajonquière (2010, p. 123). Para tanto, uma inserção com maior profundidade na proposta educativa de Itard é também objeto dessa escrita.

\section{O tratamento médico moral do garoto selvagem: uma proposta educativa}

A experiência de Itard foi descrita por ele com bastante precisão em dois relatórios, publicados em 1801 e 1806. Em seu primeiro relatório, Itard apresenta a descrição do menino selvagem, com base na avaliação realizada pelo médico Pinel. Ao chegar a Paris, Victor apresentava "seus sentidos reduzidos", de forma que seu olhar não se fixava, era insensível a sons, o olfato não discriminava odores, não falava e o tato era "restringido às funções mecânicas da apreensão dos corpos" (ITARD, 2000a, p. 131). Em relação às funçóes intelectuais, Pinel descreveu sua incapacidade quanto à atenção para objetos que não fossem de sua necessidade, ao julgamento, à memória e à imitação. Ademais, ressaltou que o menino era "desprovido de qualquer meio de comunicaçáo", "insensível a qualquer espécie de afeições morais" e, finalmente, afirma que possuía "uma vida puramente animal" (ITARD, 2000a, p. 132).

Diante dessa descrição, Itard aposta na educabilidade de Victor e estabelece cinco metas para o tratamento médico moral, que visavam estimular o interesse pela vida social, a sensibilidade dos órgáos sensoriais e a fala, além de contemplar a ampliação de suas ideias e o exercício das operaçóes mais simples da mente. Ao olharmos para os relatos dessa empreitada pedagógica, é importante que a leitura seja atravessada pelos pressupostos teóricos que orientaram o médico, a saber, as ideias de cunho empírico-sensualista, especialmente as de Condillac. Então, se consideramos que para Itard o conhecimento e as ideias advêm das sensaçóes e cada sentido deve ser estimulado isoladamente, tal qual na metáfora da estátua de mármore, é possível identificar o fio condutor de seu método. 
O primeiro relatório de Itard, escrito em 1801 após alguns meses de trabalho com Victor, é intitulado Da educação de um homem selvagem ou dos primeiros desenvolvimentos físicos e morais do jovem selvagem do Aveyron. Nessa exposição, o médico relata a história do menino, de como foi encontrado e capturado, e apresenta seus primeiros desenvolvimentos. Para descrevê-los, as cinco metas estabelecidas para o tratamento médico moral são utilizadas como norte, explicitando os progressos em cada meta separadamente. No prefácio desse relatório, Itard evidencia seu entusiasmo e reitera a aposta na educabilidade do menino.

Em seu segundo relatório, elaborado para o Ministro do Interior cinco anos depois, o médico já não demonstrava o mesmo entusiasmo. Em suas palavras, falar "do Selvagem do Aveyron é reproduzir um nome que hoje já não inspira nenhuma espécie de interesse". Itard prossegue afirmando que se não fosse a exigência desse relatório pelo Ministro "teria envolvido num profundo silêncio e condenado a um eterno esquecimento trabalhos, cujo resultado oferece bem menos a história dos progressos do aluno do que a dos insucessos do professor" (ITARD, 2000b, p. 183).

A descrição apresentada ao Ministro foi organizada a partir de três séries: I Série - Desenvolvimento das funções do sentido, II Série - Desenvolvimento das funções intelectuais e III Série - Desenvolvimento das faculdades afetivas. Para fins de análise do programa educativo proposto por Itard, utilizaremos essas três séries do último relatório, entendendo que as cinco metas, tomadas como referência para a explanação no primeiro relato, perpassam as séries descritas, uma vez que orientaram o trabalho.

Na primeira série, Desenvolvimento das funçôes do sentido, Itard retrata a maneira como exercitou, separadamente, cada um dos órgáos dos sentidos de Victor. No primeiro relatório, o médico afirma que conseguiu tornar o tato, o olfato e o paladar mais sensíveis. No entanto, não obteve o mesmo resultado com a visão e a audição, "porque esses dois sentidos, muito menos simples do que os outros, necessitavam de uma educação particular e mais longa” (ITARD, 2000a, p. 146). Por sua vez, no segundo relatório, Itard expõe como estimulou com cada sentido, com exceção do olfato que não estava em seu programa, pois considerava que esse sentido estava mais relacionado à alimentação do que ao desenvolvimento intelectual. O paladar foi estimulado para "despertar o gosto de nosso selvagem por uma profusão de pratos que até entâo desdenhara constantemente" (ITARD, 2000b, p. 195).

O estímulo da audição ocorreu através de diversos sons que o menino deveria reconhecer, enquanto permanecia vendado para isolar o sentido e se manter atento. O médico iniciou pela distinção de sons muito diferentes, partindo gradativamente para a discriminação de sons similares até adentrar em exercícios que envolviam a voz humana. Nessas últimas atividades, Victor não deveria mais reproduzir o som, precisaria somente percebê-lo e sinalizar as diferenças na pronúncia das palavras para o mestre.

Ao iniciar o relato sobre o trabalho com o sentido da visão, Itard se diz entristecido com os modestos progressos que conseguiu em relação à audição. No intuito de estimular a visão, propôs atividades de distinção de letras e palavras. Após alguns 
meses, Victor realizava a escrita e a leitura de várias palavras, de forma completamente intuitiva, sem pronunciá-las e desconhecendo seus significados, segundo a avaliação do mestre. No que concerne ao sentido do tato, Itard estimulou Victor a distinguir elementos quentes e frios e, posteriormente, objetos de formas diferentes, passando, gradualmente, para a distinção de objetos mais análogos, tal como nos exercícios para estimular a audição, até chegar à diferenciação de letras em metal. O médico conclui a descrição dessa primeira série afirmando que todos os sentidos de Victor, exceto o da audição, saíram "do seu longo embrutecimento" (ITARD, 2000b, p. 196).

A segunda série do relatório, Desenvolvimento das funçōes intelectuais, é iniciada com a afirmativa de que os acontecimentos que serão narrados estão vinculados aos fatos da série anterior, apesar de descritos separadamente, assinalando a relação entre as funçóes dos sentidos e as funçóes intelectuais. Nessa série, nos interessa particularmente o trabalho desenvolvido para que Victor viesse a falar. Em seu primeiro relatório, o médico se perguntava por que o garoto não falava se não era surdo, sendo que um grande esforço foi empreendido para a aprendizagem da fala. O estímulo da fala era a quarta meta proposta em seu programa. A dificuldade experimentada pelo mestre nessa meta é anunciada no início da descrição, quando afirma que, caso pretendesse relatar somente os bons resultados, essa meta teria sido omitida do relatório, o que não fez.

A audição foi estimulada para que Victor percebesse a voz humana, a qual era indiferente no início. Apesar dos progressos observados nesse sentido, Victor seguia não emitindo palavras e Itard assegurava que não havia lesão orgânica que justificasse tal fato. Então, as tentativas de fazer o menino falar prosseguiram. É interessante lembrar que ao estabelecer a meta para o desenvolvimento da fala, o médico pretendia que o menino expressasse suas necessidades. Diante desse objetivo, passou a estimular o menino a pronunciar a palavra água (eau em francês), que era da ordem da necessidade e possuía o som da vogal $o$, o qual chamava atenção de Victor. Itard segurava uma caneca de água diante do menino sedento, repetia a palavra água e a entregava para a pessoa que solicitasse por meio da fala. Esses esforços foram em váo, pois Victor não falou, mesmo estando com sede.

$\mathrm{Na}$ sequência, o médico modificou a palavra e passou a solicitar que Victor dissesse leite, alimento que apreciava muito. Foi com satisfaçáo que ouviu seu aluno pronunciar a palavra pela primeira vez. No entanto, essa alegria se dissipou ao perceber que o menino havia pronunciado a palavra ao avistar o leite, quando o mestre derramou o líquido na caneca, pois havia perdido a esperança de que o aluno solicitasse verbalmente. A frustração de Itard justifica-se pelo fato de o menino não ter expressado uma necessidade, ou seja, falar leite para recebê-lo porque estava com fome. Assim, conclui o mestre, "eu acabava de obter apenas uma expressão, insignificante para ele e inútil para nós” (ITARD, 2000a, p. 159). Além da pronúncia da palavra leite, Victor também dizia o nome da filha de sua governanta, Julie, e a expressão, bastante utilizada por madame Guérin, oh Dieu! 
Em seguida, Itard passa a discorrer sobre a linguagem de ação. Essa forma de comunicação é a maneira através da qual Victor expressa suas necessidades por meio de gestos, como, por exemplo, apresentar uma gamela de madeira para solicitar que lhe deem leite ou levar alguém pelo braço até o carrinho de mão para indicar que gostaria de ser empurrado. Itard considera essa forma de comunicação uma linguagem primitiva do ser humano.

O tom da descrição do trabalho realizado para desenvolver a fala no primeiro relatório é esperançoso, e Itard parece acreditar que o menino conseguirá falar, comunicando suas necessidades. No entanto, esse tom não se repete em seu segundo relatório. O médico afirma que Victor poderia ser considerado surdo, tendo em vista os obstáculos enfrentados para estimular a audiçâao. Por conseguinte, passa a buscar o desenvolvimento da fala por meio de exercícios da visão, em que o aluno deveria aprender através desse sentido o "mecanismo dos sons" e repeti-los (ITARD, 2000a, p. 215). A tentativa de oralizaçáo do menino, por meio da imitaçáo de movimentos de articulação e de sons não resultou, para o médico, em grandes progressos. Victor pronunciou apenas alguns monossílabos ininteligíveis. Diante desse fracasso, o mestre declara: "resignei-me a terminar ali minhas derradeiras tentativas em prol da fala e abandonei meu aluno a um mutismo incurável” (ITARD, 2000b, p. 216).

Por fim, na terceira série, intitulada Desenvolvimento das funçôes afetivas, Itard relata que durante muito tempo Victor não demonstrava afeto pelas pessoas, sendo indiferente mesmo àquelas que o cuidavam. No entanto, diante da ampliação de suas necessidades e dos cuidados destinados a ele, por madame Guérin e Itard, "aquele coração endurecido abriu-se afinal para sentimentos inequívocos de reconhecimento e amizade" (ITARD, 2000b, p. 219). O médico-pedagogo afirma, ainda, que o menino demonstrou afeiçóes de tristeza e alegria, próprias do homem civilizado.

\section{A experiência pedagógica de Jean Itard e a educação inclusiva de alunos com transtorno do espectro autista}

O movimento de leitura dos relatórios nos permitiu desentrelaçar alguns dos fios que formam a trama pedagógica de Itard e seu selvagem. A partir disso, é possível refletirmos sobre a presença do ideário de Jean Itard na proposta contemporânea de escolarizaçáo de alunos com transtorno do espectro autista, diante da premissa da educação inclusiva. Para tanto, propomos a discussão a partir de um ponto central: a primazia do método de ensino na proposta pedagógica de Itard. Consideramos esse ponto como um elemento, dentre outros possíveis, que oferece indícios sobre "a persistência silenciosa desse ideário entre nós”, retomando Lajonquière (2010, p. 123). Assim sendo, essa não é uma experiência que permanece cristalizada no passado, mas sim algo que vem se atualizando, de diversas formas, nas práticas pedagógicas.

$\mathrm{Na}$ análise empreendida, observamos o quão importante era para o mestre seguir o programa que se propôs a partir dos pressupostos filosóficos sobre o conhecimento e o desenvolvimento das funçôes intelectuais que adotou. Assim, os exercícios, de cunho essencialmente educativo, foram executados e repetidos, muitas vezes à exaustão, com ênfase no estímulo das sensaçôes, na imitaçáo como forma de aprendi- 
zagem e na comunicação de necessidades. A fé cega na aplicação da teoria, conforme refere Mannoni (1973), fez com que Itard desconsiderasse muitas manifestaçóes de Victor, as quais surgiam no encontro singular entre o mestre e o seu aluno.

O relato de Itard (2000a) sobre os artifícios adotados para desenvolver a fala do menino é bastante ilustrativo acerca da primazia do método para o médico-pedagogo. Inicialmente, o mestre segura a caneca de água diante do menino sedento, gritando eau, e oferecendo a caneca a quem dissesse a palavra. Victor, apesar de estar com sede, não repetiu a palavra e se agitava em frente à caneca, emitindo um som que Itard define como uma espécie de assobio. Em face ao fracasso da atividade o mestre afirma: "mudei de tema, sem, contudo, mudar de método" (ITARD, 2000a, p. 158). Entấo, o tema passa a ser a palavra leite, mas o método, inquestionado, segue o mesmo.

O interessante é que, com esse tema, o menino diz a palavra solicitada, mas náo no momento adequado, previsto no método, o que leva o mestre a considerar essa emissão outro fracasso, devendo ser "logo posto de lado" (ITARD, 2000a, p. 159). É assim que a pronúncia da palavra leite é considerada insignificante e inútil, pois não foi dita para expressar a necessidade, conforme previa o método. Outra questão pertinente é que Itard náo supôs um sentido ao ouvir essas emissóes novamente. O médico pedagogo afirma que o menino dizia leite quando estava alegre por receber o líquido e "algumas vezes ocorria-lhe pronunciá-la antes e outras vezes logo depois, mas sempre sem intenção. Tampouco atribuo importância à repetição espontânea que ele fazia dela, e que fazia ainda, no correr da noite quando vem acordar" (ITARD, 2000a, p. 159).

Nesse sentido, parecia não mais importar o momento em que Victor falasse, porque a pronúncia era considerada invariavelmente sem intenção e irrelevante. Da mesma forma, as demais emissóes do menino, Julie e Oh Dieu, ou a linguagem de ação não foram consideradas muito importantes. Inclusive a linguagem de ação era tomada como um obstáculo a ser ultrapassado. Em relação à fala, é interessante lembrarmos que são os outros que atribuem significado às primeiras emissôes de um bebê. Assim, ao dizer pela primeira vez papa, por exemplo, as pessoas que cercam esse pequeno sujeito afirmam que ele está chamando seu pai, atribuindo um sentido à palavra. Entáo, se supõe um significado que não estava ali desde o princípio, mas que passa a existir.

Essa suposição não ocorreu nos exercícios para desenvolver a fala de Victor. Parece-nos que o programa educativo proposto era baseado no treinamento. Inicialmente incentivando a imitaçáo do que o outro dizia para obter a água ou o alimento que necessitava. Em seguida, estimulando o sentido da visão, exercitando "os olhos para apreender o mecanismo dos sons, e a voz para repeti-los, mediante uma aplicação acertada de todas as forças reunidas da atenção e da imitação". Assim, mestre e aluno permaneciam um em frente ao outro "careteando" (ITARD, 2000b, p. 215).

Esses exercícios apenas treinavam uma fala dessubjetivizada, visto que Itard não oferece ao seu aluno um lugar de enunciaçáo. Para Lajonquière (2000, p. 112), 
o mestre age "[...] no sentido contrário àquele seguido intuitivamente por uma mãe que, ao metaforizar os sons emitidos pelo infans, converte este último em 'seu bebê', bem como aqueles outros, em palavras carregadas de intencionalidade". Ademais, o médico-pedagogo deixa entrever em seus relatos que também não supóe que Victor o compreendesse. Em um dos exercícios, no qual o menino não obteve êxito, o mestre perde a paciência e o chama de infeliz, afirmando que deveria retornar à floresta ou ser um inútil para a sociedade e morrer em Bicetrê. Nas palavras de Itard, disse isso como se o menino pudesse entendê-lo e segue afirmando que, caso náo conhecesse "o alcance da inteligência" do aluno, "poderia ter acreditado que fora plenamente compreendido", uma vez que, ao proferir essas palavras, ele chorou (ITARD, 2000b, p. 205).

Por meio da discussão estabelecida até o momento é possível percebermos que, na verdade, Itard elaborou um programa de ensino de maneira arbitrária para o menino selvagem. Dessa forma, o mestre não questionava as ideias de cunho empírico-sensualistas adotadas a priori, ou seja, não se deixou interrogar pelo que Victor apresentava fora do que havia sido programado ou pelo o que o menino náo aprendia. $\mathrm{O}$ fato de inclusive o nome de Victor ter sido escolhido também em função do programa, por demonstrar interesse pelo som da vogal $o$ no estímulo da audição, ilustra a primazia do método nessa experiência pedagógica.

O menino selvagem deveria comprovar as postulaçóes de uma teoria, o que cegou o mestre para as manifestações singulares de aprendizagem ou mesmo de fracassos em seu encontro com o aluno. A esse respeito, os autores Mannoni (1973) e Lajonquière (2000) sustentam que Itard não construiu nenhum aprendizado a partir de sua experiência. Lajonquière (2010, p. 138) avança em suas afirmaçôes explicando que o aluno "devia responder de acordo com os padronizados parâmetros de desenvolvimento, que todo método pedagógico supôe". No entanto, muitas atividades não obtiveram o resultado esperado e o próprio Itard "apesar do marcante entusiasmo acabou considerando que obtinha fracos progressos naquilo que mais mereceu ser chamado de adestramento do 'seu selvagem'".

Com base na análise empreendida sobre a saga pedagógica de Itard, como refere Lajonquière (2000), é possível refletirmos sobre a presença desse ideário na proposta contemporânea de escolarizaçáo de alunos com transtorno do espectro autista. Essa proposta é baseada na perspectiva da educação inclusiva, em que esses sujeitos devem frequentar o ensino comum e vem desafiando os professores em sua prática pedagógica. Em nossas experiências de acompanhamento do processo de inclusão escolar desses estudantes, observamos o quanto pode ser angustiante para os professores receber um aluno que se relaciona de maneira tão singular com os outros e com os conhecimentos escolares. O evitamento do outro, as estereotipias, os interesses peculiares, as alteraçôes na linguagem e na brincadeira, são manifestaçóes que angustiam os profissionais da educação.

Diante desse cenário permeado de angústias e incertezas, a demanda por uma metodologia adequada para o ensino desses alunos náo cessa de se repetir. Percebemos, assim, a primazia do método, táo evidente na experiência de Itard, no discurso 
dos professores de hoje. A pretensa certeza de haver um método, uma técnica para ensinar com base no diagnóstico, produz um pedido de uma resposta exata, como uma técnica para a alfabetização de autistas, por exemplo. O termo de autistas é utilizado intencionalmente, no sentido de indicar seu caráter universalizante, apoiado na premissa de que haveria um método que seria ideal para ensinar todos os autistas. Evidentemente, há peculiaridades na prática pedagógica para alunos com transtorno do espectro autista. Porém, quando associamos um diagnóstico a uma metodologia, consideramos que dessa forma se ensinam os autistas. Assim, corremos o risco, tal qual Itard, de não percebermos ocorrências peculiares no encontro de cada aluno com seu professor e sua escola.

A indicação de um determinado método pode amenizar a angústia inicial de se deparar com alunos considerados estranhos em um primeiro momento porque, por exemplo, se recusam a utilizar o lápis e a escrever, tarefa tão cara para a escola. Contudo, ao adotarmos métodos fechados, permeados de certezas, poderemos obstaculizar as manifestaçôes singulares do estudante, que emergem para além do que está previsto como correto no programa. A essas manifestaçóes é preciso dar sentido, é necessário fazer laço com o social para que não se tornem repetiçóes ou ecolalias sem significado, assim como a pronúncia da palavra leite por Victor. Essa fala nunca foi tomada como um pedido endereçado ao outro.

A primazia do método e das técnicas no cenário atual da educação inclusiva também é evidenciada em textos legais e de orientação aos sistemas de ensino com o enfoque dado aos recursos pedagógicos e de tecnologia assistiva a serem utilizados. A importância desses recursos no processo de inclusão escolar é indiscutível. Entretanto, não se restringe a eles como se ao utilizá-los a aprendizagem dos alunos estaria garantida. Nessa situação, poderíamos, assim como Itard, incorrer na ilusão de que determinadas propostas, como o estímulo dos sentidos separadamente no caso da educação de Victor, assegurariam os resultados esperados.

É preciso considerar que na educação inclusiva não se trata de ensinar estátuas de mármore, como na metáfora de Condillac. O professor se depara com alunos reais, assim como Itard deparou-se com o menino selvagem, ou seja, "[...] alguma coisa que, embora se mexesse não muito esteticamente, estava feita de carne, cabelos e ossos" (LAJONQUIĖRE, 2000, p. 109). Nesses encontros, o inesperado sempre surge, aquilo que vai além das descriçôes em manuais médicos ou documentos legais e de parâmetros determinados por propostas metodológicas. Em face disso, é preciso que o professor se deixe interrogar pelo aluno e suas manifestaçóes de aprendizagem ou de não aprendizagem para não ser seduzido pela ilusão de um controle do processo de ensino e capturado pela fé cega no método.

\section{Considerações finais}

"Itard não aprende nada com o selvagem", declara Mannoni (1973, p. 196) em sua apreciação sobre a educação de Victor. $\mathrm{Na}$ verdade, apesar dos relatórios sobre essa experiência demonstrarem a inventividade desse médico-pedagogo, a fé cega na teoria que buscava comprovar não permitiu que percebesse a relevância das manifes- 
taçóes inesperadas que ocorriam diante de seus olhos. Assim, a primazia do método, destacada neste texto como elemento de análise, é evidenciada. O foco no método, adotado a priori, e nos resultados esperados apagou a singularidade do encontro com Victor e obstaculizou a suposiçáo de sentido naquelas palavras ou comportamentos que estavam para além do planejado.

$\mathrm{Na}$ contemporaneidade, a inclusão escolar de alunos com transtorno do espectro autista impele os professores a demandar um método de ensino que garanta como resultado a aprendizagem dos conhecimentos escolares. Atentamos para a possibilidade dessa demanda repetir o cerne da proposta de Itard, que era o método. Tendo este como foco central, aquilo que é inesperado pode ser apagado ou tomado como um entrave a ser superado. É preciso lembrar que produções importantes de Victor, como a fala das palavras leite ou Julie, foram desconsideradas porque não eram emitidas conforme o esperado. Então, a escrita passou a ser a alternativa para substituir a fala, considerada insignificante e sem utilidade.

Em sua prática pedagógica, os professores precisam criar, no dia a dia da escola, estratégias para ensinar os alunos com autismo que não estão previstas em métodos fechados, completos. Essas experiências podem servir de inspiração, mas não de replicação do mesmo, pois cada encontro será único. Desse modo, se dá lugar para o estilo de aprendizagem de cada um e invençôes podem surgir, como os cantinhos na sala de aula com artefatos do universo escolar, um quadro ou papel pardo na parede para estimular a escrita daqueles que resistem a fazer registros no caderno, uma sala mais silenciosa quando o barulho ou os colegas estiverem muito invasivos, entre outras.

$\mathrm{Na}$ escola, os encontros entre o professor e os alunos com transtorno do espectro autista possibilitarão a emergência de muitas produçóes, as quais será preciso dar sentido e fazer o enlace com o social. Muitas vezes, será preciso abandonar o furor docente a fim de olhar para o processo de escolarização singular de cada aluno e apostar na aprendizagem que poderá ser construída para além de automatismos ou comportamentos socialmente aceitáveis.

\section{Referências}

BANKS-LEITE, L.; GALVÃO, I. Uma introdução à história de Victor do Aveyron e suas repercussôes. In: BANKS-LEITE, L.; GALVÃO, I. A educação de um selvagem: as experiências pedagógicas de Jean Itard. São Paulo: Cortez, 2000, p. 11-24.

CONDILLAC, E. de. Tratado das sensaçôes. São Paulo: Unicamp, 1993.

ITARD, J. Relatório I: Da educação de um homem selvagem ou dos primeiros desenvolvimentos físicos e morais do jovem Selvagem do Aveyron. In: BANKS-LEITE, L.; GALVÃO, I. A educaçáo de um selvagem: as experiências pedagógicas de Jean Itard. São Paulo: Cortez, 2000a, p. 123-177.

Relatório II: Relatório feito a Sua Excelência o Ministro do Interior sobre os novos desenvolvimentos e o estado atual do Selvagem do Aveyron. In: BANKS-LEITE, L.; GALVÃO, I. A educaçáo de um selvagem: as experiências pedagógicas de Jean Itard. São Paulo: Cortez, 2000b, p. 178-229.

LAJONQUIÈRE, L. de. Itard Victor!!! Ou do que não deve ser feito na educação das crianças. In: BANKS -LEITE, L.; GALVÃO, I. A educaçáo de um selvagem: as experiências pedagógicas de Jean Itard. São Paulo: Cortez, 2000, p. 105-116.

Figuras do Infantil: a psicanálise na vida cotidiana com as crianças. Petrópolis, RJ: Vozes, 2010.

MANNONI, O. Chaves para o imaginário. Petrópolis, RJ: Vozes, 1973. 
Taís Guareschi - Maria Inês Naujorks

\section{Correspondência}

Taís Guareschi - Universidade Federal de Santa Maria, Centro de Educação, Departamento de Educação Especial. Campus Universitário, Camobi, CEP: 97119-900 - Santa Maria, Rio Grande do Sul - Brasil.

E-mail: tais.guareschi@gmail.com - minau1990@gmail.com

Recebido em 30 de agosto de 2016

Aprovado em 30 de agosto de 2016 